\title{
Como seria ver como um ser humano?*
}

\author{
Etienne Bimbenet \\ etienne.bimbenet@orange.fr \\ Maître de conférences, Université Jean Moulin - Lyon III, Lyon, França
}

resumo Nós perguntaremos aqui "como seria ver como um ser humano". Tal questão é difícil, pois recuando um passo em relação à percepção e considerando que ela pode não ser o que é, essa questão vai de encontro àquilo que é comumente considerado como a "atitude natural". Merleau-Ponty articulou esta relativização da visão humana e seu realismo espontâneo de duas maneiras diferentes. Em primeiro lugar, há o que poderia ser chamado a "via da finitude". Ela consiste em assumir o ponto de vista de parte alguma para a percepção, o ponto de vista de um espírito sem ligações mundanas. Poder-se-ia dizer então, como Merleau-Ponty não pára de dizer, que perceber não é ver de parte alguma, e que sempre percebemos a partir de algum lugar, em um corpo finito, e não do ponto de vista de deus. Nossa origem animal, contudo, oferece uma segunda maneira completamente diferente de frustar o dogmatismo da fé perceptiva. Essa é a via adotada por Merleau-Ponty em $A$ estrutura do comportamento, onde muito naturalmente ele é levado a interrogar o que distingue a percepção animal da percepção humana. Sua resposta é valiosa: ver como um ser humano significa ser capaz de "multiplicidade perspectiva". Apreender tal conceito e encarar a visão humana como plural e como excesso, apenas é possível para quem abandonou o ponto de vista de parte alguma e decidiu filosofar começando pelo animal.

palavras-chave Percepção; origem animal; ser humano; atitude natural; multiplicidade perspectiva.

\section{A questão}

Nós nos perguntaremos aqui "como seria ver como um ser humano". Em seu famoso artigo de 1974 (NAGEL 1983, pp.193-209), Thomas

Recebido em 20 de dezembro de 2011. Aceito em 14 de fevereiro de 2012. 


\section{2}

Nagel se perguntava "como seria ser um morcego" (what is it like to be a bat). A questão era então de saber se um ser humano poderia, por imaginação, colocar-se no lugar de um morcego para sentir o que ele sente e perceber o que ele percebe. Mas, ao longo de seu artigo, ele de passagem evocava a imaginação inversa: um inteligente morcego "tentando conceber como seria ser como nós" (idem, p. 199; trad. modificada). Eis a questão - falsamente complexa, mas no entanto difícil - que gostaríamos de colocar.

A despeito das aparências, tal questão não é complexa. Ela parece sêlo porque trata-se de imaginar o que imagina um animal, ainda mais um animal que não existe: um animal de tal maneira "inteligente", como diz Nagel, a ponto de tentar um exercício de especulação filosófica que consiste em pôr-se no lugar de um ser humano. É preciso ser escancaradamente (absurdamente) filósofo para querer imaginar o que imagina um animal imaginário. Mas, de fato, a questão é simples. Se é verdade que fomos animais antes de ser homens, e se é verdade que um contínuo fio geracional liga a percepção humana à percepção animal, então é simples e legítimo perguntar-se em que se distingue a percepção humana da percepção animal. Para nós que, desde Darwin, caminhamos sobre nossos pés de seres vivos, é totalmente natural - portanto não complicado perguntar como seria ver como um ser humano ao invés de ver como um animal.

Mas a questão é, ao mesmo tempo, difícil. Trata-se, com efeito, de tomar suficiente distância em relação à nossa percepção para conceber que ela poderia ter sido diferente: trata-se, nada mais nada menos, de relativizar nossa relação com o mundo. A dificuldade é de princípio: ela diz respeito àquilo que em fenomenologia se denomina "atitude natural". A atitude natural é esta crença fundamental segundo a qual percebemos o próprio ser, e não o ser para nós. Tentar perceber a contingência de nossa percepção, ou conceber que a percepção humana surgiu historicamente como a percepção de um ser vivo particular, significa surpreender a certeza primordial ao querer que este mundo aqui seja o único mundo possível, e que o olhar humano seja uma abertura inocente sobre aquilo que é. Significa relativizar o próprio absoluto, ou aquilo que faz as vezes dele numa vida humana. Merleau-Ponty mostrou bem que cabia essencialmente (eideticamente) à nossa percepção esquecer-se como ato 
particular de um sujeito particular, e que este esquecimento exprimia negativamente a pretensão dogmática de tocar o ser em si: a percepção é em Merleau-Ponty "o ato humano que, de uma só vez, atravessa todas as dúvidas possíveis para se instalar em plena verdade" (MERLEAUPONTY 1945, p.50). A percepção recalca seu próprio relativismo, o que faz com que seja tão difícil vê-la do ponto de vista de um animal.

$\mathrm{Na}$ verdade, nossa origem animal não é a única maneira que nos é oferecida para frustrar o prestígio da atitude natural, e para ver a percepção como podendo não ser o que ela é. Uma via mais clássica se apresenta, a qual se poderia denominar "via da finitude". Esta é a via que Merleau-Ponty emprega a maior parte do tempo, em particular na Phénoménologie de la perception. Ela consiste em adotar, para a percepção, o ponto de vista de parte alguma, o ponto de vista de um espírito sem ligações mundanas; dir-se-á então, como Merleau-Ponty não pára de dizer, que perceber não é ver de parte alguma e que o ser humano não é um kosmotheoros desengajado. Percebe-se sempre a partir de algum lugar, em um corpo finito, e não do ponto de vista de deus. Como se sabe, há duas maneiras de malograr a finitude de nossa experiência em proveito de um pensamento puro: de um lado, o intelectualismo filosófico, que confunde a percepção com sua compilação conceitual; de outro lado, o fisicalismo da psicologia científica, que confunde a percepção com sua explicação causal - eis aí dois modos, conceitual e causal, de sobrevoar nossa experiência de fato e assimilá-la a um pensamento objetivo ou "em terceira pessoa". De fato, Merleau-Ponty ter-nos-á fartamente habituado à ideia de que a percepção é um ato, uma práxis em primeira pessoa que não pode se diluir nem em uma ordem de razões, nem em um mecanismo causal. Filosófica ou cientificamente, ver não é pensar: é fazer, com tudo o que está implicado de contingência e parcialidade em tal redefinição do sentir. É este o desmentido que Merleau-Ponty inflige a maior parte do tempo à segurança da percepção humana: ao perceber, somos este corpo precário e frágil (este "frágil amontoado de geléia viva" (MERLEAU-PONTY 1964, p.30), o qual se engaja no ser e para o qual, por conseguinte, nada está garantido - contrariamente àquilo em que poderiam fazer crer a reflexão filosófica ou a explicação científica.

Nossa origem animal frustra de um modo bem diferente o dogmatismo da fé perceptiva. Pois aqui não é mais o ponto de vista de deus ou 


\section{4}

de nenhuma parte que dá a medida da percepção, mas o ponto de vista do animal. A percepção humana, portanto, é relativizada de uma maneira totalmente diferente. A questão que lhe está colocada parece ter perdido altura. De uma parte, é uma questão mais local que a precedente, porque inclusa nela: quanto à finitude, a qual compartilhamos com o animal, pode-se distinguir entre sua maneira de ver e a nossa? Assim como o animal, sou este corpo que percebe, e não um pensamento desencarnado - mas como pode ser, no entanto, que tanta coisa separe nossas duas corporeidades? A questão, aliás, parece menos classicamente "filosófica" do que a primeira, pois se apoia doravante sobre um fato empírico: a evolução das espécies. Mesmo que se trate de um fato perfeitamente contingente, acontece que proviemos do animal; ora, esta proveniência fornece a ocasião para que se tome uma distância em relação à percepção humana comparável à que a filosofia toma em relação aos diferentes fenômenos que estuda. A questão, por exemplo, não é: por que o mundo, ao invés de nada? Mas: por que o mundo para o homem, ao invés do mundo para o animal? Perfilando o mundo sobre um fundo de animalidade passada, ao invés de um fundo de nada, a questão, ao que parece, é menos radical, mas, num certo sentido, mais "real", porque está referida a um evento (a hominização) que, quão contingente seja, ocorreu.

Ora, se Merleau-Ponty fala a língua da finitude na maior parte do tempo, ao menos uma vez ele empregou a via da origem animal. Ele colocou esta questão e abriu este horizonte de um modo que certamente não é anedótico, porque presente em toda sua primeira obra. Em La Structure du comportement, o ponto de vista adotado a respeito da percepção é, com efeito, o do animal. Mais particularmente, é este o caso do terceiro capítulo: ao distinguir as ordens "física", "vital" e "humana", ao remontar de uma ordem a outra como ao longo de uma scala naturae, Merleau-Ponty acabou por naturalmente questionar-se a respeito do que distingue os comportamentos animal e humano, e, mais especificamente, as percepções animal e humana. A resposta dada a esta questão reside numa fórmula preciosa, à qual gostaríamos de voltar: ver como um ser humano é ser capaz de "multiplicidade perspectiva" (MERLEAUPONTY 1942, p.133). O animal, diz Merleau-Ponty, vê o que ele vê de um ponto de vista funcional determinado: o macaco, por exemplo, vê a mesma coisa seja como um galho de árvore - revestido por exemplo de 
um valor de refúgio, em caso de agressão - seja como um bastão, que ele poderia retirar da árvore e utilizar como um instrumento de ataque. Mas ele não consegue ver esta coisa simultaneamente como um refúgio e um bastão: literalmente, ele não sabe ver "coisas" - se se entende por isso o que permanece invariante sob diferentes pontos de vista (MERLEAUPONTY 1942, p.124, 127 e 190) $)^{1}$.

Tal definição do ver "enquanto humano" representa, na verdade, uma aquisição definitiva na obra de Merleau-Ponty. Ainda que, futuramente, o essencial permanecerá circunscrever "pelo alto" o sentir - ao distingui-lo do pensamento objetivo e sublinhar a finitude do ato perceptivo - isso não diminui o fato de que o tema da multiplicidade perspectiva represente uma verdadeira criação conceitual encontrada de maneira sistemática em Merleau-Ponty - por exemplo em La Phénoménologie de la perception, quando se diz que a visão humana é "uma única visão de mil olhares”, uma visão que faz presuntivamente comunicar o aspecto atual da coisa com todos os outros aspectos possíveis. Ora, é notável que tal criação não surja do nada: ela supõe que se tenha assumido o ponto de vista do animal a respeito da percepção. O que significa que, de modo inverso, àquele que sobrevoa a experiência e a repertoria em terceira pessoa nada disso pode aparecer; ao invés da multiplicidade perspectiva, o filósofo sem origem percebe apenas um diverso sensível - de maneira alguma um ver desmultiplicado.

\section{A resposta}

Aprofundemos esta resposta.Ver como um ser humano - e não como um animal - abre o espaço de uma multiplicidade perspectiva: um espaço em que meu ponto de vista sobre a coisa pode comunicar com outros pontos de vista sobre a mesma coisa, por exemplo para refutar alguns deles ou enriquecer meu próprio ponto de vista, como acontece quando se discute. Com isto a discussão interhumana oficialmente proclama a multiplicidade perspectiva que, em toda percepção, está implicitamente em operação. A percepção é como um fórum silencioso, uma comunicação de pontos de vista sem fala em torno de um mesmo tema. Ela é uma "atenção compartilhada" - como a psicologia da infância se empe- 


\section{6}

nha em mostrar há quinze anos ${ }^{2}$-, e também como Merleau-Ponty não cessara de meditar.Vemos sempre implicitamente junto a muitos, como quando apontamos com o dedo para algo que se torna indicado para outrem: "Quando me ponho a perceber esta mesa [...], saio de minha vida individual apreendendo o objeto como objeto para todos, reúno, de uma só vez, experiências concordantes mas separadas e repartidas em vários pontos do tempo e em várias temporalidades" (MERLEAUPONTY 1945, p.50). O mundo humano é fundamentalmente interhumano, ele é, como diz Merleau-Ponty, um "intermundo" (MERLEAUPONTY 1945, p.409).

É preciso compreender bem tais tipos de expressão; é preciso deixálos desenvolver-se a partir de seu próprio horizonte teórico. Uma vez mais: se a questão da origem animal não se coloca, se se interroga a percepção classicamente - em terceira pessoa ou do ponto de vista de deus -, então nada se verá de interessante em tais declarações, nada que se assemelhe, em todo caso, a uma multiplicidade perspectiva. Notar-se-á apenas uma falta de ser em comparação com o pensamento objetivo.Ver simultaneamente de todas as partes é ver pior do que de parte alguma, o que significa recair na dispersão sensível e deixar de ver a coisa de frente. Quanto a isso, a fenomenologia husserliana da percepção parece muito sintomática. A doutrina dos perfis é o próprio tipo de definição da percepção do ponto de vista do pensamento puro: estabelecer que o sensível se estende "num diverso ininterrupto de aparências e perfis", significar anunciar um menos-ser, condenando o fato de que em todo momento o espetáculo pode revelar-se incoerente e ilusório. Tal definição do sensível, como se sabe, desenvolve-se em uma relação de oposição com o modo de ser da consciência: ao passo que o percebido se dá por perfis fluidos, a consciência, ao contrário, ao refletir percebe-se necessária, não podendo não ser no momento em que vive. À contingência do percebido se opõe a necessidade apodídica do vivido, e a multiplicidade dos perfis, se não é um estigmata da finitude, é ao menos o repositório de um saber que, por meio da redução fenomenológica, não poderá construir-se senão junto à consciência. Esta tem o privilégio de apreender-se imediatamente, enquanto a coisa sensível, ao contrário, se dispersa e foge, uma vez que, espacial e vista por um ser ele mesmo espacializado, é sempre vista de alguma parte. Perceber é decair: mensurada 
pelo metro da autoevidência da consciência, a percepção sinaliza em direção àquilo que ela não é - um saber indubitável.

Coube a Merleau-Ponty ter invertido esse esquema. Presente desde o quarto capítulo de La Structure du comportement, a Abschattungslehre de Husserl foi de chofre recebida em um sentido não husserliano. Aqui, a multiplicidade não é nada de negativo, assim como o é quando está referida à unidade de um eu penso. Merleau-Ponty não está distante de Max Scheler, que, em Le Formalisme en éthique et l'éthique matériale des valeurs, condenava o caráter puritano da noção de diverso sensível. Tal como notara Scheler, não pode haver senão inquietude e mesmo ressentimento na ideia de que no início era o caos, e que caberia ao espírito ordenar este diverso por um trabalho digno da associação empírica (Hume) ou do pensamento puro (Kant) (SCHELER 1955, pp.88-93). O mesmo ocorre em Merleau-Ponty. Desde que se o entenda por uma lacuna, não há diverso sensível: falar-se-á, antes, em multiplicidade, fazendo assim ressoar a multiplicação do ver e sua superabundância - ao invés de uma falta de ser. São testemunho estas palavras inspiradas do prefácio de Signes: "O sensível é precisamente aquilo que, sem mudar de lugar, pode frequentar mais de um corpo. [...] Tudo repousa sobre a riqueza inexcedível, sobre a miraculosa multiplicação do sensível. Ela faz com que as mesmas coisas tenham a força de ser coisas para mais de um [...] Todo o enigma está no sensível, nesta tele-visão que nos torna, no mais privado de nossas vidas, simultâneos aos outros e ao mundo" (MERLEAUPONTY 1960, pp.22-24; nós grifamos). Estamos longe, aqui, tanto de uma falta quanto de um sensível que seria salvo na unidade superior de um conceito ou de um em si. A diversidade é um bem ou uma força, é o que concerne a este corpo desmultiplicado, mimeticamente vagabundo, capaz de se identificar com qualquer vida além da sua - algo que Merleau-Ponty denomina carne. A carne, em Merleau-Ponty, nomeia um excesso, em vez do lugar de uma queda. Sem dúvida ela pode ser lida metafisicamente, como o fim do sobrevôo e a impossibilidade de um pensamento puro; mas ela é intelectualmente mais fecunda quando acolhida antropologicamente, como imbricação de meu corpo sobre os outros corpos e daquilo que eu vejo sobre o que os outros vêem. Sob esses aspectos simultaneamente noético e noemático - como corpo transgredindo seus próprios limites e como sensível partilhado, como 


\section{8}

identificação a outrem e como alteração do espetáculo -, a carne designa um aumento de si e do ver, não uma dispersão. Ela é como o corpo humano, na medida em que este corpo jamais vive ou vê sozinho: "É preciso que com o meu corpo despertem corpos associados, os "outros", que não são meus congêneres, como diz a zoologia, mas que me frequentam, os quais eu frequento, com os quais eu frequento um único Ser atual, presente, como jamais um animal frequentou seu território ou seu meio com os de sua espécie" (MERLEAU-PONTY 1988, p.13).

Antropologicamente falando, a unidade não é aquilo em que se chega, mas aquilo de que se parte. Ela é aquilo que o homem ultrapassa para constituir-se, não aquilo a partir do que ele decai. Ela é o sentir em seu estado elementar, antes de sua deflagração em um corpo humano. Como seria ver como um animal, antes da abertura de uma multiplicidade perspectiva? Merleau-Ponty, em La Structure du comportement, respondeu muito precisamente a essa questão por meio do conceito de forma (Gestalt). A percepção da forma representa o fundo vital do sentir: um animal percebe não um diverso sensível, mas um diverso de imediato totalizado, de imediato recalcado pela unidade imperiosa da Gestalt. Na verdade, a Gestalt recalca de ao menos duas maneiras o diverso sensível. A oposição entre figura e fundo, inicialmente, deixa em segundo plano tudo o que não concerne ao animal. Seguindo Kurt Goldstein em sua reinterpretação biológica da Gestalttheorie, Merleau-Ponty atribui a forma percebida à organização ativa de seu meio de vida por parte do animal (GOLDSTEIN 1951, pp.404-413). Este percebe apenas o que the concerne e aquilo a que se aplicam seus a priori específicos; ele não "vê" o restante, ou o ignora, como se diz de alguém que ignora quem é seu vizinho.Ver, para um animal, é valorizar algum aspecto da coisa em detrimento de outros, é ver a coisa a partir de alguma intenção prática, fazendo abstração do que não interessa a essa intenção, "por uma abstração vivida que deixa pura e simplesmente fora do campo sensorial do animal o que não corresponde à estrutura de seu instinto" (MERLEAUPONTY 1942, p.178). Merleau-Ponty forneceu uma descrição precisa desta "abstração vivida", desta ignorância ativa que caracteriza todo agir vivo. Trata-se de "uma consciência que roça seus objetos - diz ele -, escamoteia-os no momento em que vai estabelecê-los, e que tem isso em mente como o cego de seus obstáculos, mas que, ao invés de reconhecê- 
los, não quer saber deles, os ignora na medida em que os conhece, os conhece na medida em que os ignora, e que sustenta nossos atos e nossos conhecimentos expressos" (MERLEAU-PONTY 1960, p.291). E que se acrescente a Merleau-Ponty que este ver sem ver, que recalca o visível no momento em que o acolhe, talvez seja o que Freud procurava através da noção de inconsciente. $\mathrm{O}$ inconsciente primordial, a primeira motivação de todo recalque, seria a própria vida enquanto vê apenas o que quer ver bem, ou enquanto apenas vê o que ela própria se exibe.

A mesma observação se aplica à outra grande propriedade da forma percebida: sua transponibilidade. O mesmo acorde tonal é transponível uma oitava acima ou abaixo em um violoncelo ou piano: pouco importa a localidade sonora ou a matéria fônica nas quais ele aparece, pois uma forma é geral. Mas isso significa ainda dizer que as ocorrências de uma forma são, em sua diversidade empírica, indiferentes. A percepção de uma forma reduz a informação recebida. Ora, aqui ainda é a biologia que tem a última palavra. Como Goldstein bem mostrara, apenas importa o "comportamento privilegiado" do organismo, quer dizer, "a situação na qual os limiares sensoriais mais constantes e mais finos, na qual os movimentos necessários à situação se produzam do modo mais adequado e seguro [...], que traz consigo a distribuição da 'atenção' que conduz à melhor compreensão do mundo" (GOLDSTEIN 1951, p.407). Em uma palavra, a "boa forma" não é a mais rica ou a mais representativa do que a coisa é em sua essência, mas sim "a forma pela qual o organismo se atualiza da maneira mais conforme à sua essência” (idem, pp.406-407).É o organismo que "se impõe"3 em relação a tudo o que ele percebe, não aceitando encontrar no exterior senão o que convém a sua essência. Nas injunções que faz ao sensível, seria como se o animal fosse "formal", ao prescrever imperiosamente o que se trata de perceber, e ao imediatamente satisfazer-se com tudo o que não altere a forma geral dessa prescrição. Relido de um ponto de vista organicista, o caráter transponível da forma percebida exprime a oikeiosis animal, a aderência do animal a sua ordem própria.

Tal é, portanto, o ensinamento da Gestalttheorie. Por duas vezes ela nos fala de uma unidade liminar - mas não terminal - do sensível. A unidade não é conquista do vivente humano, seu graal descoberto pelo conceito ou pelo ato filosófico da reflexão. Num certo sentido, é o contrário que 


\section{0}

é verdadeiro. Cabe ao ver humano não unificar, mas desmultiplicar. No longo capítulo da Phénoménologie de la perception consagrado à patologia da consciência simbólica (MERLEAU-PONTY 1945, pp.130-158), todas as diferentes insuficiências resumem-se na incapacidade que os pacientes têm de afrouxar as amarras da unidade funcional, de abrir o espaço de manobra para uma multiplicidade de pontos de vista. O famoso afásico Schneider sabe fazer apenas uma coisa de cada vez. Se está na sala, não sabe colocar-se no lugar da pessoa que está na cozinha; não sabe irrealizar-se num papel de soldado, por exemplo; não sabe explicar a alguém como ir ao hospital, ainda que ele próprio vá lá todas as manhãs; em suma: não sabe estar aqui e alhures, hoje e amanhã, não sabe ser ele mesmo e um outro simultaneamente. É isso, no entanto, que nós fazemos todos os dias sem nem mesmo pensar; são "pontes de neve" que atravessamos a cada passo "sem saber como são frágeis" (MERLEAU-PONTY 1969, p.202).

A percepção humana inaugura-se com um excesso; sua lógica não é a do um, e sim a do múltiplo. Tal como o animal, estamos destinados à perspectiva, vemos sempre a partir de algum ponto. Mas o perspectivismo humano é um perspectivismo aberto, uma participação do ponto de vista atual em outros pontos de vista a respeito da mesma coisa. É precisamente em virtude desse excesso que há para nós, em sua transcendência, o real: "O perspectivismo não é imediatamente sofrido, mas conhecido como tal. Longe de introduzir na percepção um coeficiente de subjetividade, ele lhe dá, ao contrário, a segurança de comunicar com um mundo mais rico do que o que estamos aptos a julgar, quer dizer, com um mundo real" (MERLEAU-PONTY 1942, p.201). Porque a coisa é vista como podendo ser igualmente vista por outrem, ela me aparece como profunda, inesgotável, "repleta de pequenas percepções que a levam à existência” (MERLEAU-PONTY 1945, p.391). Porque eu jamais poderia cessar de rodeá-la, ela me aparece não como frágil em seu modo de ser - como na doutrina husserliana dos perfis - mas, pelo contrário, consistente, forte por todos os olhares que carrega nela - transcendente. O realismo é para nós a "atitude natural" porque somos naturalmente outros para nós mesmos, estamos despossuídos de nós mesmos desde a primeira troca de olhares, desde esta confusão nativa de corpos onde, em seus últimos cursos do Collège de 
France, Merleau-Ponty quis descobrir a raiz arcaica do simbolismo humano (MERLEAU-PONTY 1995, p.273).

\section{Mais uma vez a questão}

Voltemos, para terminar, à forma geral da questão: como seria ver como um ser humano, e não como um animal? Recuemos um pouco e perguntemos o que tal questão provoca à filosofia. Filosoficamente falando, em que essa questão é diferente, por exemplo, desta questão mais clássica que evocávamos acima: como seria perceber, e não pensar? Pode-se perguntar, com efeito, o que distingue a via da origem animal da via da finitude, e porque seria absolutamente preciso jogar uma via contra outra. Vemos ao menos três razões para fazê-lo.

1. Parece-nos absurdo que, cento e cinqüenta anos depois de Darwin, se persevere em pensar metafisicamente ou do ponto de vista de deus; o ponto de vista do animal oferece uma alternativa filosoficamente mais convincente, ainda que, como vimos, o que a motive seja um fato empiricamente contingente. E já significa muito que um fato real (a evolução das espécies e, mais precisamente, a hominização), e não uma crença ou uma hipótese, venha provocar a filosofia e convidá-la a pensar de modo diferente. Medir o homem pelo absoluto do pensamento objetivo foi a maneira de filosofar da Idade clássica - como Foucault bem mostrou (FOUCAULT 1966). Em Descartes, o homem é pensado pelo que the falta, como irredutível à clara distinção entre as substâncias pensante e extensão; "pratica-se" o homem no uso da vida, em vez de pensá-lo; é-se homem ao confundir-se, na união da alma e do corpo, o que a clara luz do entendimento distinguira tão bem. A existência se deduz privativamente da essência, e o finito do infinito; a antropologia não possui nenhuma autonomia. Ora, talvez seja verdade que a antropologia não tenha nenhuma autonomia, mas por outra razão: porque surgimos da vida "criados pelas feras” (RACHELS 1990), e não por um deus. Não foi uma queda que nos fez homens, mas um processo histórico constatável empiricamente, o qual se pode, ainda que grosseiramente, datar e relatar. $\mathrm{O}$ ponto de vista da origem animal pode por si engajar a filosofia pela via de um verdadeiro espanto, quase infantil: nos espantamos com o que ocorreu. 
2. A paisagem mental altera-se completamente quando se coloca a questão antropológica ao invés da questão clássica. Esta última é fundamentalmente uma questão metafísica, no sentido em que nela se opõem dois mundos: o mundo daqui e o de lá, cá na terra e além. Se se decide definir a metafísica dessa maneira, pelo seu "meta", então estamos em pleno metafísico quando pensamos a percepção como finita em oposição à perfeição do pensamento objetivo. Pois, invariavelmente, encontrar-seá dois mundos, aquele do sensível e o do inteligível, o do corpo e o do espírito, o da natureza e o da liberdade, etc. E que se note bem que não basta jogar a terra contra o céu - o sensível contra o inteligível ou o corpo contra um espírito separado - para crer que se acabou com a metafísica. Ela sobrevive muito além de sua aparente revogação, se é verdade que, ao destituir o além em proveito do cá na terra, permanece intacta a própria paisagem opositiva. Escolher a terra contra o céu, ou a encarnação contra o sobrevôo, significa pensar ainda metafisicamente na cisão de dois mundos. Essa é a razão pela qual, ainda que contra sua vontade, Merleau-Ponty seja às vezes tão metafisico: sua propensão filosófica é naturalmente descendente, uma vez que advoga como "não-filósofo" contra uma filosofia abstrata ou separada (MERLEAU-PONTY 1960, pp.198-199).

Por que a via da origem animal teria o poder de enfim nos desembaraçar da metafísica e de nos reconciliar com este mundo aqui, na medida em que é o único mundo possível? É que, em verdade, a espacialidade do pensamento é aqui totalmente diferente. Não se trata mais de opor o sensível ao inteligível, ou o corpo ao espírito; não se trata do fim sem fim da metafisica. A paisagem antropológica talvez seja tão opositiva quanto a paisagem metafísica, mas de acordo com uma tópica totalmente diferente: a de si e de outrem que si, ao invés da tópica do alto e do baixo - de fundo mitológico. O animal está aderido ou é apropriado a si; tudo que acontece fundamentalmente lhe acontece; tudo que ele percebe the concerne, conta positiva ou negativamente para ele; seu meio de vida (Umwelt) é composto por tudo que ele constitui a partir de seus a priori específicos. Neste caso, o conceito de Umwelt deve ser pensado espacialmente, como mundo "envolvendo" (Um-) o organismo. É preciso repensar o corpo humano conforme essa espacialidade. Nosso corpo não é a morada de um espírito, mas uma carne excêntrica a si mesma, uma carne 
que, por oposição ao egocentrismo vital, nos descentra em relação a nós mesmos. Na abertura de uma multiplicidade perspectiva, na comunicação de pontos de vista sobre a coisa assim como na multiplicação de aspectos da coisa, na identificação a outrem como na visada de um mundo transcendente, experimenta-se o rompimento do ć́rculo vital. Assumir o mundo ou pretender que ele exista, significa visar outra coisa e algo mais que um Umwelt, significa tomar o partido da transcendência e não o do açambarcamento. Assim, a atitude natural e a superabundância do ver que a sustenta não visam algo mais além deste mundo; elas opõem o descentramento ao egocentrismo ou o esquecimento de si ao concernimento; elas correspondem, na história da vida, a uma verdadeira revolução copernicana que nos faz gravitar ao redor do mundo - quando, ao contrário, todas as coisas gravitavam ao redor do animal.

3. Possuímos uma terceira e última razão para não encarar metafisicamente a percepção: é que pressuporíamos o que há por mostrar. De fato, o pensamento objetivo ou o olhar desengajado exibem-se o realismo mas este último, enquanto atitude humana fundamental, é precisamente o que se deve deduzir. Lembremos o sentido de nossa questão. Nós nos perguntamos: como o realismo é possível? Como um vivente primitivamente centrado em si mesmo pôde se abrir a outra coisa além de si, deixar-se transbordar por uma multiplicidade perspectiva e visar um real em excesso sobre si mesmo? Esta é a questão aberta por La Structure du comportement. Ora, o grande mérito dessa obra é colocar direito a questão. Nela começa-se pelo concernimento animal; a multiplicidade perspectiva ou a visada realista vêm ao fim, como uma instituição que chegou tarde na história da vida. Dito de outra maneira, o realismo não está pressuposto, mas implicitamente posto entre parênteses, por uma forma de redução "zoológica" do fenômeno humano - por uma recondução do realismo humano às condições animais de seu surgimento. No fundo, Merleau-Ponty aparenta-se àquilo que se tornará, nos anos 80, a máxima da psicologia evolucionista: to make the natural seem strange ${ }^{4}$. Por conseguinte, fazer com que o que nos parece natural torne-se estranho, desde que recolocado sobre o fundo de nossa pré-história. MerleauPonty, em La Structure du comportement, terá conseguido fazer com que o mais natural - dito de outra maneira, a própria atitude natural - apareça como o menos evidente. Ele terá aberto esta possibilidade filosófica numa 
forma de repetição naturalizante do gesto husserliano. Husserl coloca entre parênteses o realismo e quer compreendê-lo a partir de um pensamento puro; Merleau-Ponty, por sua vez, suspende o realismo e quer compreendê-lo a partir do claro-escuro da intencionalidade vital - este saber sem saber da percepção animal. Este leve deslizamento da fenomenologia no interior de si mesma, raramente notado, representa uma brecha filosófica maior, por muito tempo oferecida à meditação.

* Agradeço as sugestões de Anderson Gonçalves e José Luiz Neves (nota do trad.).

1 Merleau-Ponty se inspira aqui no famoso trabalho de W. Köhler, L'Intelligence des singes supérieurs (1917), trad. fr. P. Guillaume, Paris, Alcan, 1927; mas também nas experiências de I. Meyerson e P. Guillaume sobre a utilização de instrumentos pelos chimpanzés, o instrumento sendo definido justamente como aquilo que, não estando "ligado a tal situação especial [...], vale para mil situações possíveis" (cf. "Recherches sur l'usage de l'instrument chez les singes", Journal de Psychologie normale et pathologique, 3-4, 1930 ; 7-8, 1931 ; 7-8, 1934 ; 5-8, 1937).

2 Cf. Joint Attention. Its Origine and Role in Development, C. Moore et P. J. Dunham (dir.), Hilsdale, New Jersey and Hove, Lawrence Erlbaum Associates, 1995 ; igualmente N. Eilan, C. Hoerl, T. McCormack et J. Roessler (dir.), Joint Attention: Communication and other minds. Issues in Philosophy and Psychology, Oxford, Clarendon Press, 2005.

3 CANGUILHEM 1992, p. 143 : “O organismo é considerado como um ser ao qual nada pode ser imposto, porque sua existência como organismo consiste em ele próprio oferecer-se às coisas segundo certas orientações que lhe são próprias".

${ }^{4}$ L. Cosmides e J.Tooby, «Evolutionary Psychology: a Primer», http:/www.psych.ucsb..edu/research/cep/primer.html, Center for Evolutionary Psychology, 1997.

\section{Referências bibliográficas}

CANGUILHEM, G. 1992. "Le vivant et son milieu ", in La

Connaissance de la vie, Paris : J.Vrin.

FOUCAULT, M. 1966. Les Mots et les Choses. Paris : Gallimard.

GOLDSTEIN, K. La Structure de l'organisme, trad. E. Burckhardt e J. Kuntz. Paris : Gallimard. 
NAGEL, T. 1983. "What is it like to be a bat ?" in Questions mortelles, trad. P. Engel e C. Engel-Tiercelin, Paris, PUF, 1983 e Philosophical Review, n93, oct. 1974.

MERLEAU-PONTY. 1942. La Structure du comportement. Paris : PUF. 1945. Phénoménologie de la perception. Paris :

Gallimard. 1960. Signes. Paris : Gallimard. .1964. Le visible et l'invisible. Paris : Gallimard. 1969. La Prose du monde. Paris : Gallimard. 1988. L'Oeil et l'Esprit. Paris : Gallimard (Folio). .1995. La Nature. Cours du Collège de France. Paris

: Editions du Seuil.

RACHELS, J. 1990. Created from animals. The Moral Implications of Darwinism. Oxford : Oxford University Press.

SCHELER, M. 1955. Le Formalisme en éthique et l'éthique matériale des valeurs, trad. fr. M. de Gandillac. Paris : Aubier. 